\title{
Outcome of Rigo-Chêneau type brace treatment for adolescent idiopathic scoliosis - using the Scoliosis Research Society brace studies inclusion criteria
}

\author{
T Maruyama*, H Yamada, Y Nakao \\ From 9th International Conference on Conservative Management of Spinal Deformities - SOSORT 2012 \\ Annual Meeting \\ Milan, Italy. 10-12 May 2012
}

\section{Background}

We have been using Rigo-Chêneau type brace for the treatment of idiopathic scoliosis since 2007. Curves other than the upper thoracic main curve were the subjects of the treatment. To analyze the outcomes of the brace treatment, use of the standardized inclusion criteria is essential.

\section{Aim}

To evaluate outcomes of Rigo-Chêneau type brace treatment using the Scoliosis Research Society (SRS) AIS brace studies inclusion criteria, which includes patients with age 10 years or older when the brace is prescribed, Risser 0 -II, primary curve magnitude $25^{\circ}-40^{\circ}$, and no prior treatment.

\section{Results}

A total of 32 patients, 27 females and 5 males, met the SRS inclusion criteria. Average age at the beginning of the treatment was 12.0 years (10 to 15). Risser sign was 0 in13, I in 7, and II in 12 patients. Curve pattern was thoracic $(\mathrm{T})$ in 12, thoracolumbar or lumbar (TL) in 12 and double (D) in 8 patients. Average Cobb angle before treatment was $30.9^{\circ}$. Initial correction rate by the brace was $53.5 \%$ on an average $(42.4 \%$ for $\mathrm{T}, 77.4 \%$ for $\mathrm{TL}$, and $34.8 \%$ for D curve). Most patients wore their brace as part-time, at home or at night. The average follow-up period was 19 months. Of 32 patients, 15 reached skeletal maturity during the treatment period. Four of them (27\%) progressed more than $6^{\circ}$, and two of them (13\%)

Dept of Orthopaedic Surgery, Saitama Medical Center, Saitama Medical University, Saitama, Japan exceed $45^{\circ}$. Only one patient underwent surgical treatment during the study period.

\section{Conclusion}

Although the number of patients who reached skeletal maturity was relatively small, $73 \%$ of their curve could be stabilized by the treatment. Rigo-Chêneau type brace was effective for the treatment of adolescent idiopathic scoliosis.

\section{Published: 3 June 2013}

\section{Reference}

1. Richards BS, Bernstein RM, D'Amato CR, Thompson GH: Standardization of criteria for adolescent idiopathic scoliosis brace studies: SRS Committee on Bracing and Nonoperative Management. Spine 2005, 30(18):2068-2075, discussion 2076-2067.

doi:10.1186/1748-7161-8-S1-O44

Cite this article as: Maruyama et al:: Outcome of Rigo-Chêneau type brace treatment for adolescent idiopathic scoliosis - using the Scoliosis Research Society brace studies inclusion criteria. Scoliosis 2013 8(Suppl 1):O44.

Submit your next manuscript to BioMed Central and take full advantage of:

- Convenient online submission

- Thorough peer review

- No space constraints or color figure charges

- Immediate publication on acceptance

- Inclusion in PubMed, CAS, Scopus and Google Scholar

- Research which is freely available for redistribution 